\title{
Transoral diverticulostomy with a modified Endo-Gia stapler: results after 4 years of experience
}

\author{
R. A. Lang $\cdot$ F. W. Spelsberg $\cdot$ H. Winter \\ K.-W. Jauch · T. P. Hüttl
}

Published online: 22 June 2007

(C) Springer Science+Business Media, LLC 2007

\section{Erratum to: Surg Endosc DOI 10.1007/s00464-006-9036-4}

Figures 3 and 4 of this article (Surgical Endoscopy, Vol. 21, No. 4, April 2007, pp. 532-536) were published erroneously. The correct figures are displayed below. Springer regrets the error.

The online version of the original article can be found under doi:10.1007/s00464-006-9036-4

\footnotetext{
R. A. Lang $(\bowtie) \cdot$ F. W. Spelsberg · H. Winter . K.-W.Jauch · T. P. Hüttl

Chirurgische Klinik und Poliklinik der Ludwig-MaximiliansUniversität, Klinikum Großhadern, Marchioninistrasse 15, 81377 München, Germany

e-mail: Reinhold.Lang@med.uni-muenchen.de

F. W. Spelsberg

e-mail: Fritz.Spelsberg@med.uni-muenchen.de

H. Winter

e-mail: Hauke.Winter@med.uni-muenchen.de

K.-W.Jauch

e-mail: Karl.Jauch@med.uni-muenchen.de

T. P. Hüttl

e-mail: Thomas.Huettl@med.uni-muenchen.de
}

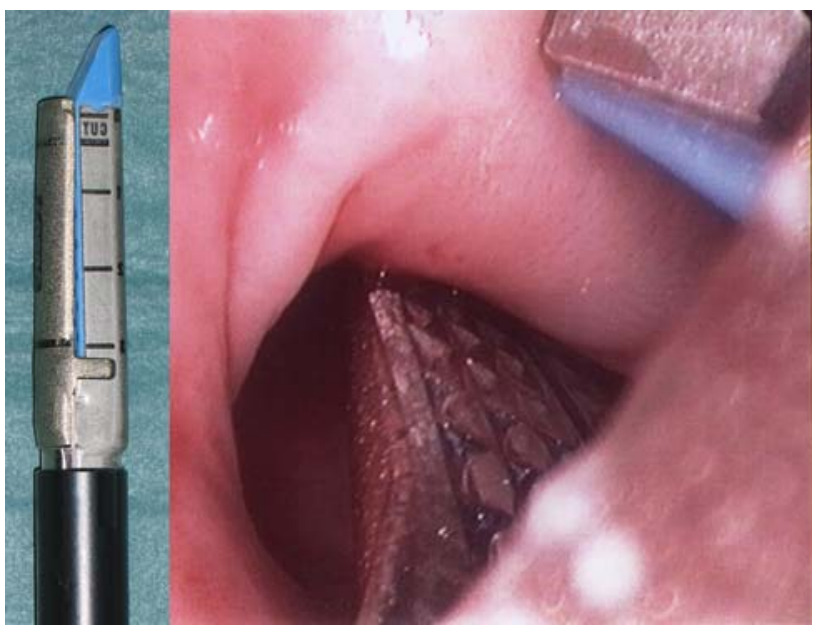

Fig. 3 Modified stapler with shortened counterpressure plate for the transoral diverticulostomy

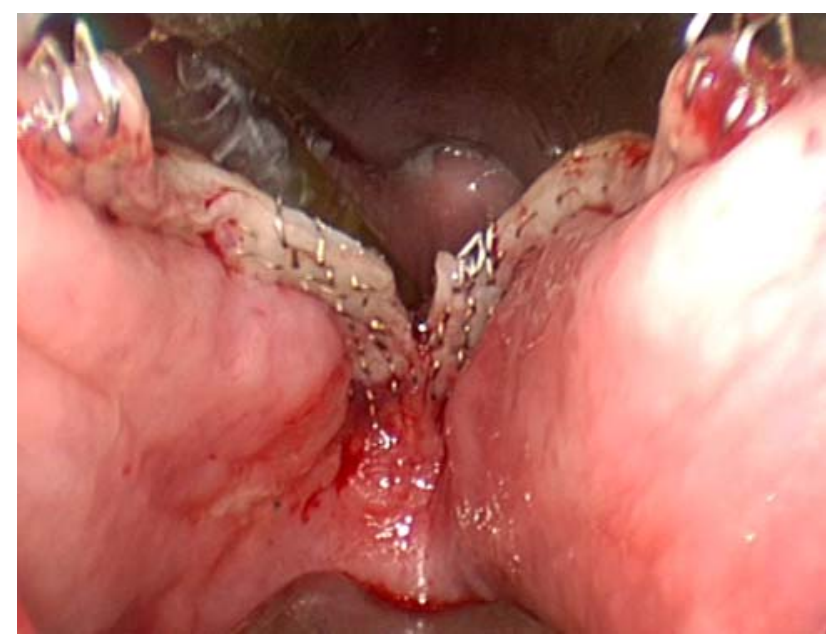

Fig. 4 Stapler anastomosis using a modified Endo-Gia stapler with shortened anvil 